Article

\title{
Hydroconversion of Aromatic Hydrocarbons over Bimetallic Catalysts
}

\author{
Aleksandr Glotov * $\mathbb{D}$, Valentine Stytsenko, Maria Artemova, Michail Kotelev $\mathbb{D}$, Evgenii Ivanov, \\ Pavel Gushchin $\mathbb{D}$ and Vladimir Vinokurov
}

Department of Physical and Colloid Chemistry, Gubkin Russian State University of Oil and Gas, 119991 Moscow, Russia; vds41@mail.ru (V.S.); artemovamai@gmail.com (M.A.); kain@inbox.ru (M.K.); ivanov166@list.ru (E.I.); guschin.p@mail.ru (P.G.); vinok_ac@mail.ru (V.V.)

* Correspondence: glotov.a@gubkin.ru; Tel.: +7-499-507-90-32

Received: 9 March 2019; Accepted: 22 April 2019; Published: 24 April 2019

check for

updates

\begin{abstract}
Bimetallic catalysts (BMC) for hydroconversion of aromatic hydrocarbons (ArH) have been designed by modification of $\mathrm{Ni} / \mathrm{Al}_{2} \mathrm{O}_{3}$ with chromium(0) compounds and phosphoromolybdic heteropolyacid (HPA). Catalysts were tested in hydrogenation of benzene and toluene, in hydrodemethylation of pure toluene and they were shown to possess a high activity, selectivity and sulfur tolerance under conditions of the processes above. The activity of $\mathrm{BMC}$ in these processes was much higher as compared with that of two-component (Ni-Cr, Ni-HPA) or conventional $\mathrm{Ni} / \mathrm{Al}_{2} \mathrm{O}_{3}$ catalysts. Using BMC, hydrogenation of benzene and toluene proceeds with activity increased (up to 34-38 mol $/ \mathrm{kg} \cdot \mathrm{h}$ ) and toluene hydrodemethylation may be performed with improved selectivity $(90.3 \%)$ and benzene yield $(81 \%)$. The high sulfur tolerance of BMC was demonstrated by performing hydrodemethylation of toluene containing up to $500 \mathrm{ppm} \mathrm{S.}$
\end{abstract}

Keywords: aromatics; hydrogenation; hydrodemethylation; bimetallic catalysts; synergistic activity

\section{Introduction}

Aromatic hydrocarbon fractions $\mathrm{C}_{6}-\mathrm{C}_{8}$ (referred to as BTX) are usually produced from catalytic processes in refineries, such as fluid catalytic cracking, naphtha reforming, and thermal cracking various petroleum fractions. Benzene is the most valuable component in BTX for producing such chemicals as cyclohexane and ethylbenzene that are intermediates in caprolactam and styrene production, respectively [1-3]. Unlike benzene, toluene is of limited application, so conversion of the latter (and also $\mathrm{C}_{7}-\mathrm{C}_{9}$ aromatics) to benzene is desirable for producing petrochemicals [4,5]. On the other hand, in refineries, motor fuel hydroprocessing including dearomatization is a large-scale process, which scope permanently increases, as environmental limitations become more severe [6-8].

Main characteristics of catalysts for hydrogenating aromatics are activity and sulfur tolerance. Catalysts based on $\mathrm{Pt}[9,10]$ and $\mathrm{Pd}[11,12]$ are the most active, however they have a rather low sulfur tolerance. For example, Pt-Ru significantly lose their hydrogenating activity in the presence of thiophene: 2-6 times for $57 \mathrm{ppm} \mathrm{S}$ and dozen times for $560 \mathrm{ppm} \mathrm{S} \mathrm{[10].} \mathrm{To} \mathrm{increase} \mathrm{the} \mathrm{sulfur}$ tolerance, a combination of $\mathrm{Pd} /$ zeolite A- Pd/zeolite $\mathrm{Y}$ was proposed [11] or the use of beta-zeolite [12] as a support for Pd. However, these techniques provide only partial problem solving, and catalytic activity decreases, e.g., for naphthalene and tetralin hydrogenation losses of activity are about $40 \%$ (for 500 ppm S) [11] and 10-90\% (for $200 \mathrm{ppm} \mathrm{S)} \mathrm{[12].} \mathrm{The} \mathrm{new} \mathrm{approach} \mathrm{comprises} \mathrm{obtaining}$ active sulfide phase in situ during the reaction inside porous aromatic frameworks (PAF) as supports. The NiWS phase obtained has high hydrogenating activity and sulfur tolerance, but the preparation process of such catalysts is a very complicated and time-consuming task. Firstly, PAF materials are synthesized by Suzuki cross-coupling reaction between tetrakis-[p-bromophenyl]methane and 
1,4-phenylenediboronic acid or 4,4'-biphenyldiboronic acid. Then the process includes infiltration of PAF with a salt $\left[(\mathrm{n}-\mathrm{Bu})_{4} \mathrm{~N}\right]_{2} \mathrm{Ni}\left(\mathrm{WS}_{4}\right)_{2}$ and further decomposition thereof to form the NiWS phase [13].

Therefore, the main catalytic systems having the high sulfur tolerance are conventional sulfide $\mathrm{NiMoS}_{\mathrm{x}}$ and NiWS $\mathrm{S}_{\mathrm{x}}$ catalysts $[14,15]$. However, these catalysts have a good activity only at hard conditions: $\mathrm{T}>600 \mathrm{~K}$ and hydrogen pressure $3 \mathrm{MPa}$ and higher. Therefore, despite of a lot of works devoted to hydrogenating aromatics [9-17] and phenols [18-20], there is a demand for high active, selective, and stable catalysts, which application provides more effective removal of aromatics.

In the case of hydroconversion of alkylaromatics at high temperatures, the main pathway is hydrodealkylation. Supported nickel catalysts show good activity, but in the case of ethylbenzene hydrodealkylation at temperatures above $870 \mathrm{~K}$ the intensive benzene ring opening proceeds, and process selectivity sharply decreases. As a result, to achieve benzene selectivity $>50 \%$, the aromatics conversion should be as low as 10\% [21]. The most promising catalytic systems described in the literature include at least two metals selected from groups VIII (Ni, Co) and VI (Cr, Mo, W) [22]. Using such catalysts, it is possible to perform effective fuel hydroprocessing under high pressure of hydrogen. Unfortunately, such catalysts show the slope opposition, namely, their selectivity increases at the expense of aromatics conversion. It is also known from patent literature methods for toluene catalytic dealkylation with hydrogen and steam using Rh-Zn [23] and Rh-Ni [24] supported over $\mathrm{Al}_{2} \mathrm{O}_{3}$. These processes show good performances, but they perform only with feed of highest purity, because catalysts are very sensitive to traces of sulfur $(<0.1 \mathrm{ppm})$ and water $(<10 \mathrm{ppm})$. Pt/H-ZSM-5 catalyst for dealkylation of $\mathrm{C}_{9+}$ aromatics has also low tolerance with respect to poisons above [25]. As for commercial thermal processes Pirotol and Detol using a $\mathrm{Cr}_{2} \mathrm{O}_{3} / \mathrm{Al}_{2} \mathrm{O}_{3}$ catalyst, they are of low activity even at temperature of $820 \mathrm{~K}$ and higher, where significant cocking of feed proceeds $[16,17,22]$.

This study is focused on synthesis of alumina-based bimetallic catalysts with Ni nanoparticles covered by chromium compounds (Ni-CrA) as well as modified by HPA and lithium salt of HPA (LiHPA). These catalysts were investigated in hydrogenation of benzene and toluene as well as hydrodemethylation of toluene as model reactions. Additionally, the Ni-CrA-LiHPA catalyst was tested in toluene hydrodemethylation with thiopene added to the feed for evaluation of sulfur tolerance.

The properties of $\mathrm{Ni}-\mathrm{CrA}$ were quite different from conventional $\mathrm{Ni}-\mathrm{Cr}$-catalysts by magnetization, lack of chemisorption of oxygen, and moreover, Ni-CrA-HPA had very high synergistic activity in hydrogenation of aromatics. In case of toluene hydrodemethylation, the new catalysts were shown to possess the activity of at least dozen times more that of commercial catalyst $\mathrm{Cr}_{2} \mathrm{O}_{3} / \mathrm{Al}_{2} \mathrm{O}_{3}$; by selectivity and activity they were close to Rh-catalyst, but having much more sulfur tolerance.

\section{Results and Discussion}

Eight different catalysts having various composition and adsorption properties were compared (Table 1). BMC were prepared by decomposition of hexacarbonyl chromium $(\mathrm{CrCO})$ or bis(arene)chromium compounds (CrA) over $\mathrm{Ni} / \mathrm{Al}_{2} \mathrm{O}_{3}$.

Table 1. Adsorption data for alumina supported Ni-containing catalysts of various composition.

\begin{tabular}{|c|c|c|c|c|}
\hline No. & Catalyst (wt. \%) & $\begin{array}{l}\text { BET Surface Area, } \\
\mathrm{m}^{2} / \mathrm{g}\end{array}$ & $\begin{array}{c}\mathrm{O}_{2} \text { Consumption, } \\
\mu \mathrm{mol} / \mathrm{g}\end{array}$ & $\begin{array}{c}\text { Ni Specific Surface } \\
\text { Area, } \mathrm{m}^{2} / \mathrm{g}\end{array}$ \\
\hline 1 & $4 \mathrm{Ni}$ & 130 & 58 & 3.5 \\
\hline 2 & $4 \mathrm{Ni}-3 \mathrm{CrA}$ & 131 & 2.5 & 0.15 \\
\hline 3 & $4 \mathrm{Ni}-7 \mathrm{CrA}$ & 132 & 2.1 & 0.13 \\
\hline 4 & $4 \mathrm{Ni}-3 \mathrm{CrA}-5 \mathrm{HPA} *$ & 135 & 2.7 & 0.16 \\
\hline 5 & $4 \mathrm{Ni}-3 \mathrm{CrA}-5 \mathrm{LiHPA}$ * & 133 & 2.4 & 0.14 \\
\hline 6 & $10 \mathrm{Ni}$ & 128 & 166 & 9.9 \\
\hline 7 & $10 \mathrm{Ni}-1.5 \mathrm{CrCO}$ & 129 & 18.2 & 1.1 \\
\hline 8 & $7 \mathrm{CrA}$ & 132 & 0 & - \\
\hline
\end{tabular}

${ }^{*} \mathrm{H}_{4} \mathrm{PMo}_{11} \mathrm{VO}_{40}$. 
To elucidate peculiarities of chromium distribution, the magnetization and chemisorption of oxygen were measured for alumina supported samples, including mono- and bimetallic compositions.

Table 1 presents data of surface for catalysts examined. As shown, all catalysts possess about the same BET surface area (128-135 $\left.\mathrm{m}^{2} / \mathrm{g}\right)$, but consumption of $\mathrm{O}_{2}$ by $\mathrm{Ni}-\mathrm{Cr}$ samples sharply decreases, and Ni specific surface falls by an order of magnitude (cf. data of Samples 6 and 7).

The effect of organochromium compounds is even more pronounced, and the number of $\mathrm{Ni}$ atoms exposed toward oxygen being greatly decreased (cf. data of Samples 1-5). It should be noted that neither hydrogen, nor oxygen reacts with $\mathrm{CrA} / \mathrm{Al}_{2} \mathrm{O}_{3}$ sample. One may propose that decomposition of chromium compound is localized on the surface of nickel crystallites [26]. Due to the low diffusivity of $\mathrm{Cr}$ in the Ni lattice [27], all Cr-containing species (CrA, $\mathrm{CrCO}$ ) cover Ni particles. As a result, the Ni particles are almost unavailable to both $\mathrm{O}_{2}$ and $\mathrm{H}_{2}$.

The specific distribution of chromium provides unusual magnetic properties of Ni-Cr system. The data of measurements (Figure 1) show that the addition of chromium results in a great increase of magnetization, which conflicts with the data reported for conventional $\mathrm{Ni}-\mathrm{Cr}$ alloys [28]. It is generally known that metallic $\mathrm{Ni}$ and $\mathrm{Cr}$ may form an alloy and intermetallide $\mathrm{Ni}_{3} \mathrm{Cr}$. As for magnetization (B) of these compounds, it decreases to zero at ratio $\mathrm{Cr} / \mathrm{Ni} \sim 0.08$ for solid solution and $\mathrm{B} \sim 0$ for $\mathrm{Ni}_{3} \mathrm{Cr}$, because of paramagnetic nature thereof.

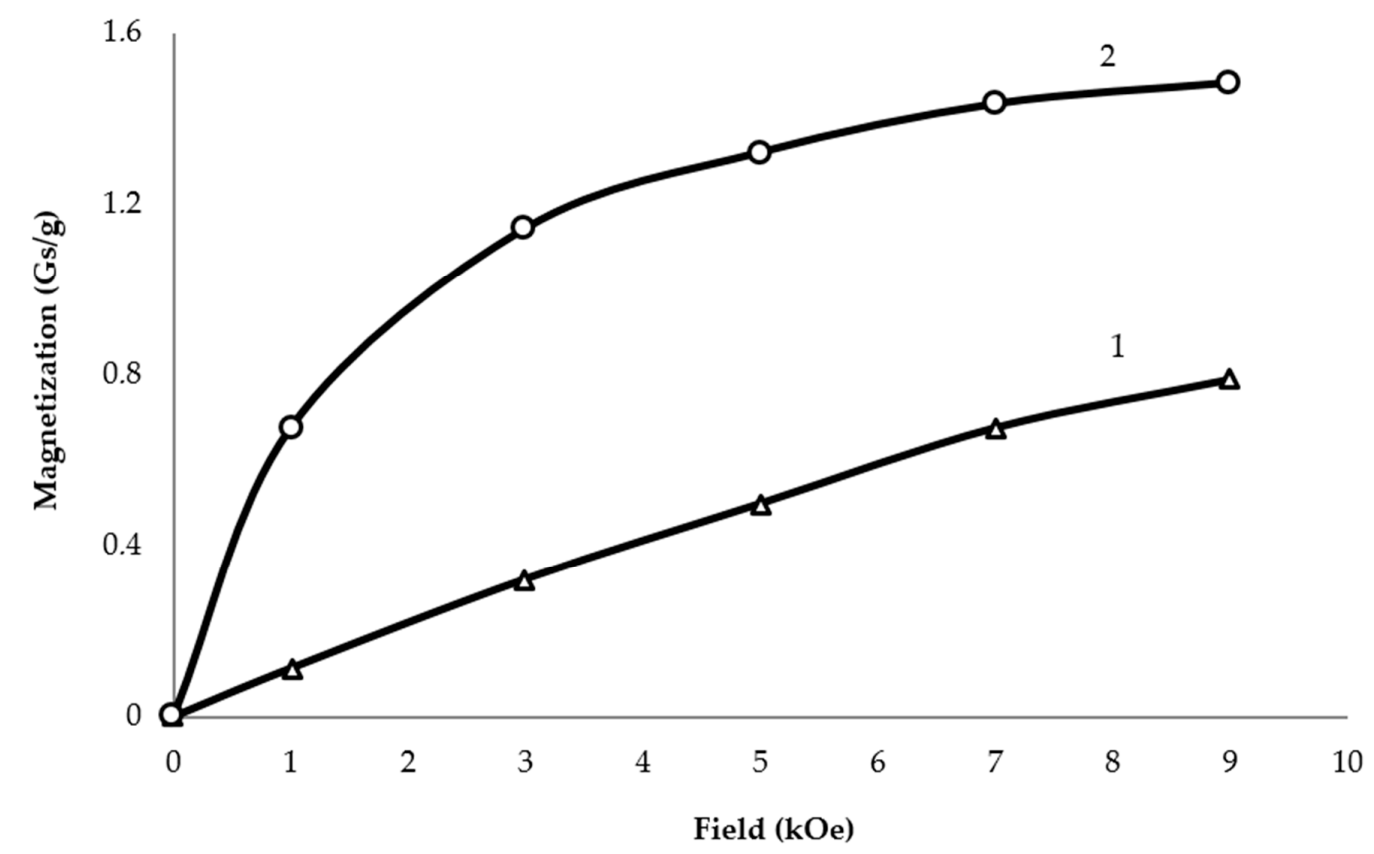

Figure 1. Magnetization curves for $10 \% \mathrm{Ni} / \mathrm{Al}_{2} \mathrm{O}_{3}(1)$ and $10 \% \mathrm{Ni}-1.5 \% \mathrm{Cr} / \mathrm{Al}_{2} \mathrm{O}_{3}$ (2).

As opposed to the known compounds, magnetization of Ni-Cr samples, obtained by decomposition of $\mathrm{CrCO}$ (or $\mathrm{CrA}$ ) on the Ni metal surface, significantly increases in magnetic field. This unusual behavior may be explained by very high dispersivity of $\mathrm{Cr}$ particles, with facile domains orientation in magnetic field [29], according to TEM data. As seen from Figure 2, Ni and Cr belong to the same region of nanoparticles having the size of $2-10 \mathrm{~nm}$ and with greater predominance for the size of $4 \mathrm{~nm}$. It should be noted, however, that the size of $\mathrm{Cr}$ particles is much lower than that of Ni particles (cf. $\mathrm{Cr}$ and $\mathrm{Ni}$ pictures in Figure 2A). Based on data presented, one may infer that $\mathrm{Ni}-\mathrm{Cr}$ samples have a core-shell structure being observed in Ni-Cr nanoparticles [30]. 

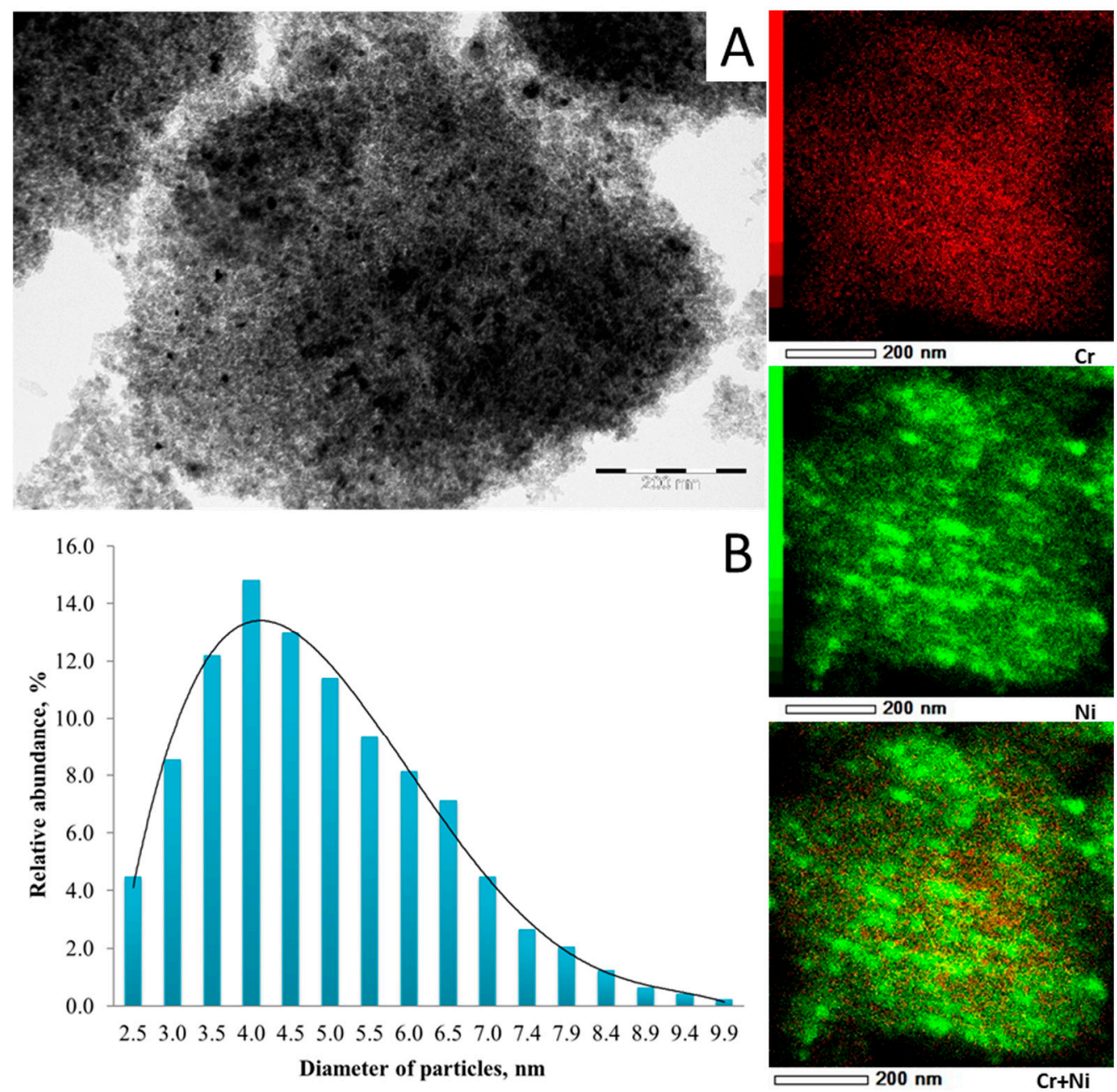

Figure 2. TEM image (A) and particles distribution (B) in $10 \% \mathrm{Ni}-1.5 \mathrm{CrCO} / \mathrm{Al}_{2} \mathrm{O}_{3}$ sample.

Figure $3 \mathrm{~A}$ shows the $\mathrm{XRD}$ profile from $10 \% \mathrm{Ni}-1.5 \mathrm{CrCOAl}_{2} \mathrm{O}_{3}$. The metallic Ni peaks are a primary phase in the sample $\left(44.4,51.82,76.38^{\circ} 2 \theta\right)$ [31], but the wide peak at $37.28^{\circ} 2 \theta$ and shoulder in the range of 60.6-63.24 $2 \theta$ closely match the most prominent peaks for $\mathrm{NiAl}_{2} \mathrm{O}_{4}$ spinels [31,32]. Peaks at 19.5 and $32.66^{\circ}$ correspond to nickel aluminum oxide phases as the impurity phase. The close interaction between $\mathrm{NiO}$ and $\mathrm{Al}_{2} \mathrm{O}_{3}$ at high temperatures can cause the formation of nickel aluminate [32].

In addition, three broad peaks at $2 \theta=37.5,45.62$ and $66.8^{\circ}$ in the XRD curve indicated the presence of $\gamma-\mathrm{Al}_{2} \mathrm{O}_{3}$ [33]. It was suggested that the catalysts prepared by decomposition of $\mathrm{Cr}(\mathrm{CO})_{6}$ or organochromium compounds are composites of metallic $\mathrm{Ni}$ and $\mathrm{NiAl}_{2} \mathrm{O}_{4}$ spinels with impurity of nickel aluminum oxides.

The presence of $\mathrm{NiAl}_{2} \mathrm{O}_{4}$ was corroborated by TPR experiments. Since the interaction between $\mathrm{NiAl}_{2} \mathrm{O}_{4}$ and the support is stronger than that of between $\mathrm{NiO}$ and the support, the spinel exhibits a higher temperature of reduction [33]. This fact is clearly indicated by TPR profile of $10 \% \mathrm{Ni}-1.5 \mathrm{CrCO} / \mathrm{Al}_{2} \mathrm{O}_{3}$ sample (Figure 3B). We observed a broad peak in the range of $620-1150 \mathrm{~K}$ with three maxima at 735, 800 and $1015 \mathrm{~K}$. The first one corresponds for $\mathrm{NiO}$ nanoparticles supported on alumina, the next peak to the surface $\mathrm{NiAl}_{2} \mathrm{O}_{4}$ phase, and third to the bulk spinels in the cavities of alumina with an areas ratio $=30: 55: 15$ respectively $[34,35]$.

Therefore, $10 \% \mathrm{Ni}-1.5 \mathrm{CrCO} / \mathrm{Al}_{2} \mathrm{O}_{3}$ catalyst contains more than $85 \%$ of surface nickel, and ultrahigh dispersive chromium particles being included between nickel nanoparticles (size of 2-10 nm). 


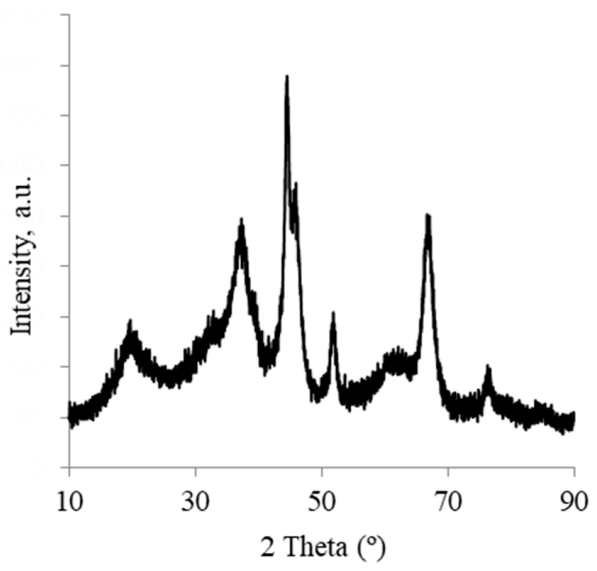

(A)

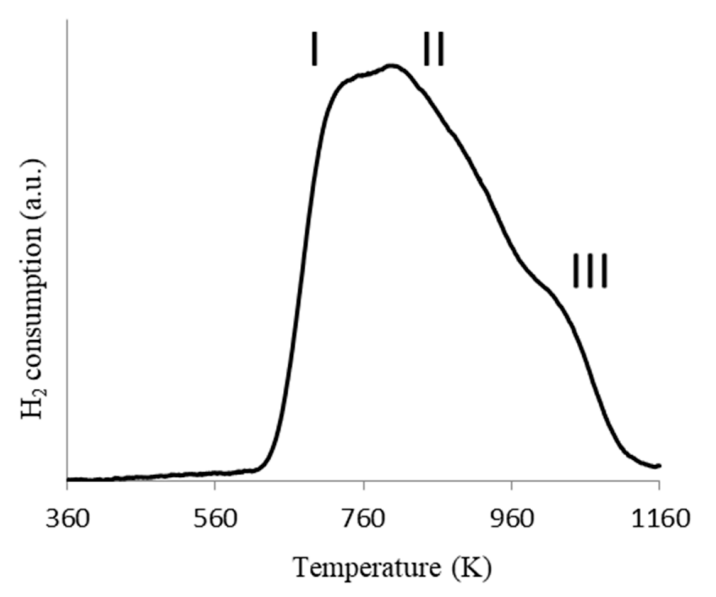

(B)

Figure 3. X-ray diffraction pattern (A) and TPR profile of $10 \% \mathrm{Ni}-1.5 \mathrm{CrA} / \mathrm{Al}_{2} \mathrm{O}_{3}$ sample (B).

It may be expected, therefore, that these samples will also possess very interesting performance as the catalysts. Table 2 shows the results obtained on testing Ni-containing catalysts in hydrogenation of benzene and toluene.

Table 2. Benzene and toluene hydrogenation over alumina supported Ni-containing catalysts; weight hourly space velocity (WHSV) $5 \mathrm{~h}^{-1}$, pressure $0.1 \mathrm{MPa}\left(\mathrm{H}_{2} / \mathrm{ArH}=10\right)$.

\begin{tabular}{cccccc}
\hline \multirow{2}{*}{ Sample No. } & Catalyst/ArH & \multirow{2}{*}{ T, K } & Conversion, $\%$ & \multicolumn{2}{c}{ Activity } \\
\cline { 5 - 6 } & & & & $\mathbf{m o l} / \mathbf{k g} \cdot \mathbf{h})$ & $\mathbf{1 0}^{\mathbf{2}} \cdot \mathbf{s}^{\mathbf{- 1} \mathbf{\$}}$ \\
\hline 1 & $4 \mathrm{Ni} / \mathrm{Bz}$ & 370 & 4.6 & 5.7 & 2.6 \\
2 & $4 \mathrm{Ni}-3 \mathrm{CrA} / \mathrm{Bz}$ & 370 & 5.6 & 7.0 & 39 \\
3 & $10 \mathrm{Ni} / \mathrm{Bz}$ & 370 & 6.1 & 7.5 & 1.2 \\
4 & $10 \mathrm{Ni}-1.5 \mathrm{CrCO} / \mathrm{Bz}$ & 370 & 12.4 & 15.2 & 22 \\
5 & $10 \mathrm{Ni}-1.5 \mathrm{CrCO} / \mathrm{Tol}$ & 370 & 14.0 & 17.1 & 24.8 \\
6 & $4 \mathrm{Ni}-7 \mathrm{CrA} / \mathrm{Bz}$ & 420 & 1.0 & 1.25 & 3.2 \\
7 & $4 \mathrm{Ni}-7 \mathrm{CrA} / \mathrm{Tol}$ & 420 & 1.15 & 1.44 & 3.7 \\
8 & $4 \mathrm{Ni}-3 \mathrm{CrA}-5 \mathrm{HPA} / \mathrm{Bz}$ & 370 & 27.1 & 33.7 & 187 \\
9 & $4 \mathrm{Ni}-3 \mathrm{CrA}-5 \mathrm{HPA} / \mathrm{Tol}$ & 370 & 30.5 & 38.1 & 211 \\
10 & $\mathrm{CrA} / \mathrm{Bz}(\mathrm{Tol})$ & $370-570$ & 0 & 0 & - \\
11 & $\mathrm{HPA} / \mathrm{Bz}(\mathrm{Tol})$ & $370-570$ & 0 & 0 & - \\
\hline
\end{tabular}

It is obvious from Table 2 that after surface modification of nickel-containing catalysts with chromium their bulk hydrogenation activity significantly increases from 1.22 to 2 times (cf. sample No. 1-2 and 3-4). If the decrease of the active surface $\mathrm{S}_{\mathrm{Ni}}$ after modification is considered, the specific activity $\left(\mathrm{A} / \mathrm{S}_{\mathrm{Ni}}\right)$ increases more than tenfold. It should be stressed, however, that both $\mathrm{CrA} / \mathrm{Al}_{2} \mathrm{O}_{3}$, and $\mathrm{HPA} / \mathrm{Al}_{2} \mathrm{O}_{3}$ are inactive over temperatures studied. It can be inferred, therefore, that the increase of catalytic activity observed for modified Ni-Cr catalysts is due to formation of new sites with finest distribution of chromium sub-nanoparticles over $\mathrm{Ni} / \mathrm{Al}_{2} \mathrm{O}_{3}$ (Figure $2 \mathrm{~A}$ ). It is worth mentioning the sharp increase in activity of samples containing phosphoromolybdic heteropolyacid (cf. Samples 1-2 and 8-9). The effect is well observable both in bulk and specific hydrogenation activity, and being as high as 5 times. This synergistic effect of activity observed for modified Ni-Cr-HPA may be explained by activation of adsorbed aromatics with HPA, because the reactivity of ArH in hydrogenation is correlated with the concentration of the medium strength acid sites, as known for supported Ru/ [5] and Au-Pd/silica-alumina [36] catalysts. It is noteworthy that hydrogenating activity of modified $\mathrm{Ni}-\mathrm{Cr}-\mathrm{HPA}$ catalyst based on active metal $-0.014 \mathrm{~mole} /(\mathrm{min} \cdot \mathrm{g})$ is very close to that of $\mathrm{Pt}_{90} \mathrm{Ni}_{10} / \mathrm{MCM} 1$ $-0.015 \mathrm{~mole} /(\mathrm{min} \cdot \mathrm{g})$ [9] at $370 \mathrm{~K}$, but our catalyst is free of noble metal. 
Another feature of $\mathrm{Ni}-\mathrm{CrA} / \mathrm{Al}_{2} \mathrm{O}_{3}$ catalyst is a stable operation even at low ratios $\mathrm{H}_{2} / \mathrm{ArH}$ such as 3.5. Usually, Ni-containing catalysts suffer from self-poisoning with ArH during hydrogenation thereof. Kinetically, this effect results in a negative reaction order with respect to aromatics $[3,37]$. Therefore, to maintain the catalytic activity, high ratios $\mathrm{H}_{2} / \mathrm{ArH}$ are required. In contrast to $\mathrm{Ni} / \mathrm{Al}_{2} \mathrm{O}_{3}$, where intensive retardation of benzene hydrogenation occurs at ratios $\mathrm{H}_{2}$ / benzene $<10$, in case of $\mathrm{Ni}-\mathrm{CrA} / \mathrm{Al}_{2} \mathrm{O}_{3}$, this ratio may be as low as 4.0 [38]. The effect may be explained by decrease of strong benzene-Ni interaction due to core-shell structure [39] of $\mathrm{Ni}-\mathrm{Cr}$ catalysts derived from $\mathrm{Cr}(\mathrm{CO})_{6}$ or $\mathrm{CrA}$ (see Figure 2A). As a result, self-poisoning with $\mathrm{ArH}$ is excluded and hydrogenation of aromatics may be performed at lower ratios of $\mathrm{H}_{2} / \mathrm{ArH}$.

In the case of toluene hydroconversion at higher temperatures, the second pathway is possible, namely, hydrodemethylation. The main factor of toluene hydrodemethylation is the selectivity. It is known that the selectivity of conventional nickel-containing catalysts is poor because an intensive aromatic ring opening proceeds [21].

For this reason, in determining the range of shifting the reaction pathway, we have applied the $\mathrm{Ni}-\mathrm{CrA}$ catalyst and monitored toluene hydroconversion up to $750 \mathrm{~K}$. Figure 4 presents the result obtained under pressure of $0.75 \mathrm{MPa}$ and WHSV $=1.5 \mathrm{~h}^{-1}$.

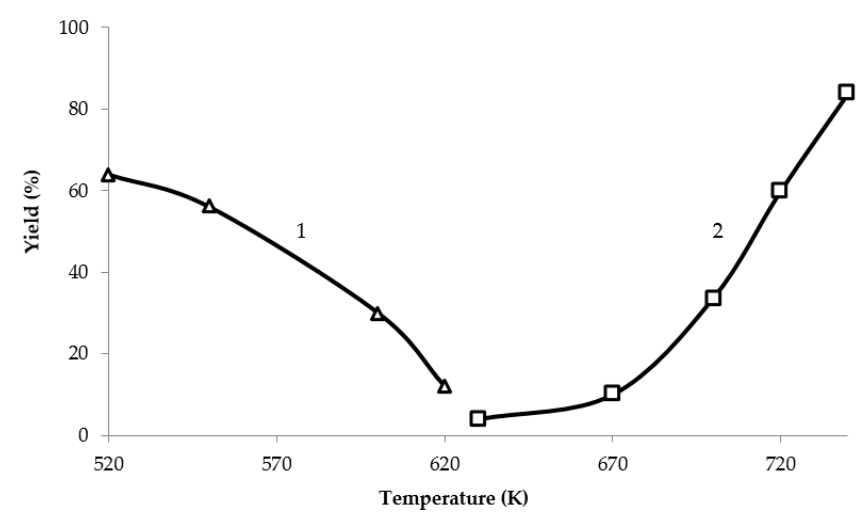

Figure 4. Toluene hydroconversion over $\mathrm{Ni}-\mathrm{CrA} / \mathrm{Al}_{2} \mathrm{O}_{3}$ under hydrogen pressure $0.75 \mathrm{MPa}$ and $\mathrm{WHSV}=1.5 \mathrm{~h}^{-1}$. (1) - methylcyclopentane and (2) - benzene.

As Figure 4 shows, toluene hydrogenation proceeds up to $620 \mathrm{~K}$ with selective formation of methylcyclohexane ( $>99 \%)$. The hydrodemethylation process starts at $630 \mathrm{~K}$ with formation of benzene and methane. Data presented in Table 3 show that modification of nickel by chromium provides a great improvement of selectivity and stability thereof. Whereas toluene is totally cracked over $\mathrm{Ni} / \mathrm{Al}_{2} \mathrm{O}_{3}$ at $680 \mathrm{~K}$, after modification by chromium, the Ni-CrA/ $\mathrm{Al}_{2} \mathrm{O}_{3}$ catalyst acquires a good selectivity of $85 \%$. In the case of this process, however, we have not found that acid modification of $\mathrm{Ni}-\mathrm{CrA} / \mathrm{Al}_{2} \mathrm{O}_{3}$ improves the catalyst performance, and the only effect being some decrease of selectivity.

Table 3. Toluene hydrodemethylation over alumina supported Ni-containing catalysts WHSV $=1.5 \mathrm{~h}^{-1}$. Pressure 0.7 $\mathrm{MPa}\left(\mathrm{H}_{2} /\right.$ Toluene $\left.=5\right)$.

\begin{tabular}{ccccc}
\hline Metal Loading (\%) & Temperature, $\mathbf{K}$ & $\begin{array}{c}\text { Toluene } \\
\text { Conversion, } \%\end{array}$ & $\begin{array}{c}\text { Activity } \\
\text { (mol/kg.h) }\end{array}$ & $\begin{array}{c}\text { Benzene } \\
\text { Selectivity, \% }\end{array}$ \\
\hline 10 Ni-1.5 CrCO & 650 & 99.9 & $\#$ & $<1$ \\
4 Ni & 680 & 99.9 & $\#$ & $<1$ \\
4 Ni-3 CrA & 720 & 70.3 & 34.4 & 85.2 \\
4 Ni-3 CrA-5 & 733 & 77.1 & 37.7 & 80 \\
HPA & 753 & 90.9 & 44.3 & $62^{\#}$ \\
4 Ni-3 CrA-5 & 733 & 85.3 & 41.6 & 92.3 \\
LiHPA & 753 & 89.8 & 43.8 & 90.3 \\
\hline
\end{tabular}

" Deactivation due to cocking. 
For understanding the scheme of hydrodemethylation and ring opening processes, the set of experiments was performed at higher toluene conversions $\left(X_{T} 40-90 \%\right)$ with variation of contact time (WHSV range of 1.5-4.5 $\mathrm{h}^{-1}$ ). The results obtained are set out in Figure 5 as a dependence of benzene selectivity $\left(\mathrm{S}_{\mathrm{B}}\right)$ from toluene conversion.

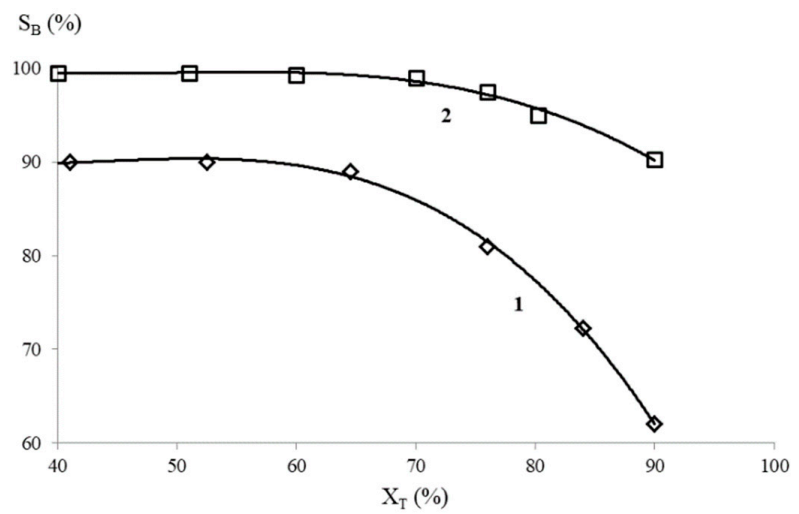

Figure 5. Toluene conversion to benzene under temperature $753 \mathrm{~K}$, pressure $0.75 \mathrm{MPa}$ and WHSV $=1.5-4.5 \mathrm{~h}^{-1}$ over $\mathrm{Ni}-\mathrm{CrA} / \mathrm{Al}_{2} \mathrm{O}_{3}$ catalysts promoted with HPA (1) and LiHPA (2).

As Figure 5 shows, benzene selectivity is actually constant up to toluene conversion of $60 \%$. It means that hydrodemethylation and ring opening proceed as parallel reactions, and the ratio of their intensity $\left(k_{1} / k_{2}\right)$ being $\geq 10 / 1$. However, at toluene conversions more than $60 \%$, benzene is also decomposed by consecutive reaction, with its selectivity being dropped.

$$
\mathrm{CH}_{4} \stackrel{\mathrm{k}_{2}}{\leftarrow} \text { Toluene } \stackrel{\mathrm{k}_{1}}{\rightarrow} \text { Benzene } \stackrel{\mathrm{k}_{3}}{\rightarrow} 6 \mathrm{CH}_{4}
$$

One may suppose that Reactions 1, 3, and 2 proceed over different sites of catalyst, and benzene hydrocracking to methane (Reaction 3 ) being proceed on acidic sites. In this case, some decrease of catalyst acidity may suppress the ring opening process, and as a result, benzene selectivity will be improved.

The results obtained for catalyst modified by mono-Li salt of HPA are presented in Table 3 and Figure 5. These data confirm the assumption above on the role of acidic sites in benzene hydrocracking. As a matter of fact, the use of LiHPA salt instead of heteropolyacid suppresses Reaction 3 and benzene selectivity increases from $62 \%$ to $90.3 \%$. Therefore, we may conclude that Ni-CrA-LiHPA catalyst developed has high activity $\left(\sim 3.8 \mathrm{~h}^{-1}\right)$ that is at least dozen times more that of commercial catalyst $\mathrm{Cr}_{2} \mathrm{O}_{3} / \mathrm{Al}_{2} \mathrm{O}_{3}$, and high selectivity that is actually the same as for Rh-catalysts known in the art. Moreover, in contrast to the most active catalytic systems based on $\mathrm{Rh}$, the catalyst developed has a much higher sulfur tolerance (see Table 4 and Figure 6). Actually, during $33 \mathrm{~h}$ testing of toluene hydrodealkylation in the presence of thiophene (up to $500 \mathrm{ppm} \mathrm{S}$ ) we observe only a minor decrease of toluene conversion (about $2 \%$ ), and benzene selectivity being practically the same, in the range of $90-91 \%$.

Table 4. Toluene Hydrodealkylation over alumina supported catalysts.

\begin{tabular}{cccc}
\hline Entry & Rh-Zn [23] & Rh-Ni [24] & Ni-CrA-LiHPA \\
\hline Temperature (K) & 828 & 843 & 753 \\
Pressure (MPa) & 4.0 & 1.0 & 0.7 \\
WHSV $\left(\mathrm{h}^{-1}\right)$ & 4.0 & 4.0 & 1.5 \\
Toluene conversion, $\%$ & 90 & 85 & 91 \\
Benzene selectivity, $\%$ & 75 & 90 & 90.3 \\
Sulfur tolerance $(\mathrm{ppm})$ & $<1$ & $<1$ & $\sim 500^{*}$ \\
\hline
\end{tabular}




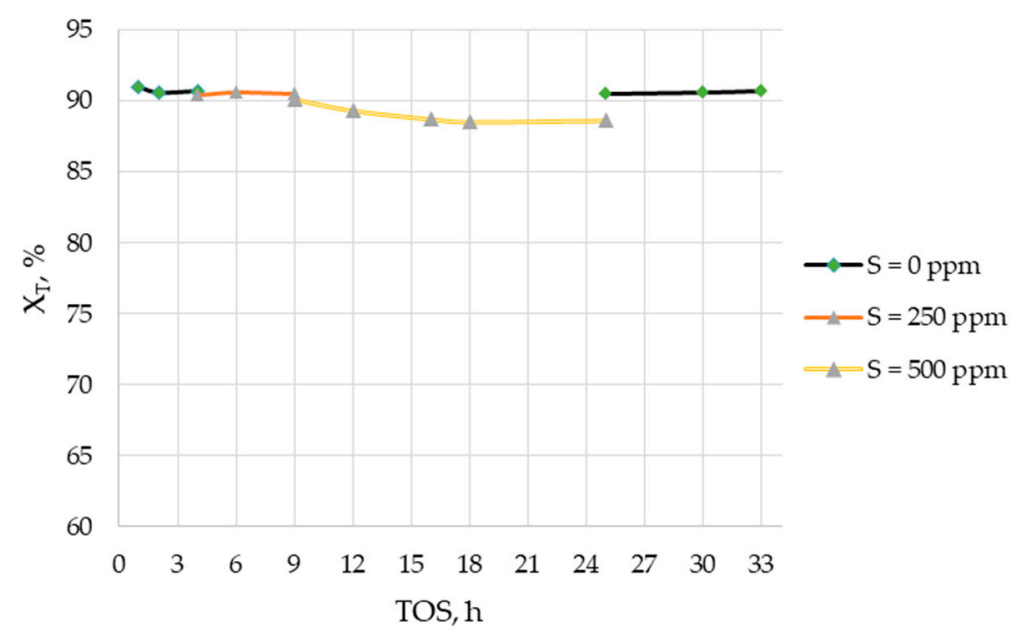

Figure 6. Sulfur tolerance of Ni-CrA-LiHPA catalyst for toluene hydrodealkylation: $\mathrm{T}=753 \mathrm{~K}, \mathrm{P}=0.7$ MPa, WHSV $1.5 \mathrm{~h}^{-1}$.

Figure 6 presents toluene conversion for time on stream (TOS) test of $33 \mathrm{~h}$ in the presence of various sulfur concentrations (as a thiophen). As Figure 6 shows, addition of thiophen ( $250 \mathrm{ppm} \mathrm{S)} \mathrm{has}$ no effect on toluene conversion, but it slightly decreases (at most $2 \%$ ) at higher thiophen concentration (500 ppm S). It should be noted that this effect is a reversible one, and the catalyst activity being restored on operation with sulfur-free toluene in $3 \mathrm{~h}$. We may conclude, therefore, that Ni-CrA-LiHPA catalyst has high sulfur tolerance.

\section{Materials and Methods}

\subsection{Chemical Reagents}

- $\quad$ Microspherical $\gamma$ - $\mathrm{Al}_{2} \mathrm{O}_{3}$ (SKTB grade) grain size $0.5-0.8 \mathrm{~mm}, \mathrm{~S}=210 \mathrm{~m}^{2} / \mathrm{g}$

- Hexacarbonyl chromium and bis-arene chromium chemically pure (Reachim)

- $\mathrm{LiNO}_{3}, \mathrm{Ni}\left(\mathrm{NO}_{3}\right)_{2} \cdot 6 \mathrm{H}_{2} \mathrm{O}, \mathrm{H}_{4} \mathrm{PMo}_{11} \mathrm{VO}_{40}$ - each chemically pure (Aldrich)

- Benzene, toluene-each chemically pure (Reachim)

- $\mathrm{Ar}, \mathrm{H}_{2}, \mathrm{He}, \mathrm{N}_{2}$ - spec. pure from gas cylinders being purified in cold traps filled with CaA zeolite.

\subsection{Catalyst Preparation}

The initial catalyst, $\mathrm{Ni} / \mathrm{Al}_{2} \mathrm{O}_{3}$, was prepared by the standard impregnation procedure [40] starting from microspherical $\gamma-\mathrm{Al}_{2} \mathrm{O}_{3}$ and nickel nitrate followed by calcination $\left(450{ }^{\circ} \mathrm{C}, 6 \mathrm{~h}\right)$, and reduction $\left(\mathrm{H}_{2}, 500^{\circ} \mathrm{C}, 3 \mathrm{~h}\right)$. Bimetallic catalysts were prepared by decomposition of hexacarbonyl chromium or bis(arene)chromium compounds ( $\mathrm{CrA}$ ) in hydrogen flow over prereduced $\mathrm{Ni} / \mathrm{Al}_{2} \mathrm{O}_{3}$ or over alumina (for comparison) as described earlier [26]. Decomposition of $\mathrm{Cr}(\mathrm{CO})_{6}$ or $\mathrm{CrA}$ was monitored by chromatography and mass-spectrometry, analyzing the concentrations of methane and benzene in the effluent $\mathrm{H}_{2}$. Catalysts modified with heteropolyacid (HPA) were prepared by impregnation of bimetallic catalysts with ethanol solution of $\mathrm{H}_{4} \mathrm{PMo}_{11} \mathrm{VO}_{40}$ or its monolithium salt (LiHPA). The latter was prepared by exchange reaction of $\mathrm{HPA}$ with $\mathrm{LiNO}_{3}$ as described in article [41]. Finally, all the modified catalysts were treated in hydrogen flow at $500{ }^{\circ} \mathrm{C}$ for $3 \mathrm{~h}$.

\subsection{Analyses and Instrumentations}

Transmission electron microscopy (TEM) analysis was performed using a Jem-2100 microscope (Jeol, Akishima, Japan) with electron tube voltage of $100 \mathrm{kV}$. The count of particle sizes was performed by processing microimages obtained using Image-Pro Plus 6.0 program. 
The content of each element contained in catalysts was determined by atomic absorption spectroscopy (Perkin-Elmer AAS, Waltham, MA, USA) after mineralization of samples. All percentages are indicated as weight percentages.

The surface area of catalysts was measured by the standard BET method using Gemini VII 2390 setup (Micromeritics, Norcross, GA, USA). For evaluation of the specific surface of $\mathrm{Ni}\left(\mathrm{S}_{\mathrm{Ni}}\right)$ hydrogen-oxygen titration was performed on Micromeritics AutoChem 2950HP. The procedure was as follows: at first, all samples were treated with $\mathrm{H}_{2}(673 \mathrm{~K}, 2 \mathrm{~h})$ followed by He flow $(298 \mathrm{~K}, 0.5 \mathrm{~h})$ to remove gaseous $\mathrm{H}_{2}$ from the system. Then adsorbed hydrogen was titrated with oxygen pulses (3\% $\mathrm{O}_{2-}-97 \% \mathrm{He}$ ) in He flow. The amount of oxygen reacted was determined with catharometer, and water formed being analyzed with QMS 200 mass-spectrometer (Stanford Research Systems, Sunnyvale, CA, USA). This amount was used to calculate the $\mathrm{S}_{\mathrm{Ni}}$ value (in $\mathrm{m}^{2} / \mathrm{g}$ ) using the stoichiometry O:Ni $=1: 1$.

Temperature-programmed reduction (TPR) was performed on Micromeritics AutoChem 2950HP analyzer (Micromeritics, Norcross, GA, USA). Before the analysis, $100 \mathrm{mg}$ samples were pretreated at $673 \mathrm{~K}$ for $30 \mathrm{~min}$ under Ar flow in order to remove water and other contaminants, and then cooled to $333 \mathrm{~K}$. The reduction step was performed under the $30 \mathrm{ml} / \mathrm{min}$ flow of $8 \mathrm{vol} \% \mathrm{H}_{2}-92 \mathrm{vol} . \% \mathrm{Ar}$ mixture in the range from 333 to $1173 \mathrm{~K}$ with heating rate of $10 \mathrm{~K} / \mathrm{min}$. The consumption of $\mathrm{H}_{2}$ was calculated using the AutoChem HP V2.04 program.

Phase analysis of catalysts was performed using X-ray powder diffractometer Bruker D2 (Billerica, MA, USA), $\mathrm{Cu} \mathrm{K \alpha}(\lambda=1.5406 \AA), 2 \theta$ values varied from $5^{\circ}$ to $90^{\circ}$.

The static magnetization of samples was measured by the Faraday method using a vacuum balance "Setaram" in fields from 10 to 15,000 Oe at $20^{\circ} \mathrm{C}$ taking into account a correction for diamagnetism of quartz ampoule and support. For magnetization measurements a sample $(30 \mathrm{mg})$ was placed in ampoule, reduced under standard conditions, evacuated to $10-^{4} \mathrm{~Pa}$ at $400{ }^{\circ} \mathrm{C}$ for $1 \mathrm{~h}$, then ampoule was sealed.

The catalytic activity of the freshly reduced catalysts was tested in a flow type setup at temperatures 370-750 K, pressures 0.1-1.0 $\mathrm{MPa}$, and $\mathrm{H}_{2} / \mathrm{ArH}$ ratio of 3.5 to 90 . All the experiments were performed in the kinetic-controlled range [38]. The conversion and reaction rates were calculated based on product concentrations that were determined by on-line GC $(20 \mathrm{~m} \times 0.15 \mathrm{~mm}$ capillary column with OV-17 phase, Sigma-Aldrich, St Louis, MO, USA). The conversion, $\mathrm{X}$, was determined as the amount of reacted aromatics ( $\mathrm{ArH}$ ) divided by the amount of $\mathrm{ArH}$ introduced in the reactor. The hydrogenation selectivity, S, to cyclohexane (methylcyclohexane) was determined as the amount of cyclohexane (methylcyclohexane) formed divided by the amount of reacted benzene (toluene) respectively.

In case of toluene hydrodemethylation, the benzene selectivity was determined by formula:

$$
\mathrm{S}_{\mathrm{B}}=\frac{7}{6+\mathrm{n}\left(\frac{\mathrm{S}_{\mathrm{M}}}{\mathrm{S}_{\mathrm{B}}}\right)}
$$

where $S_{M}$ and $S_{B}$ are methane and benzene peak areas in the chromatogram respectively and $n=4.875$ - chromatography calibration coefficient.

The benzene yield, $Y_{B}$, was calculated as the product of toluene conversion and the benzene selectivity.

The sulfur tolerance in toluene hydrodemethylation was studied in the presence of thiophene at $753 \mathrm{~K}$ and hydrogen pressure of $0.7 \mathrm{MPa}$. A sulfur-free feedstock was initially fed for $3 \mathrm{~h}$, until steady state was established. Then sulfur poisoning experiments were performed using thiophene solution in toluene (equivalent of total sulfur content of 250 or $500 \mathrm{ppm}(\mathrm{v} / \mathrm{v})$ ). Finally, the sulfur-free feedstock was used again for $3 \mathrm{~h}$, to check for any change of catalyst activity.

\section{Conclusions}

Bimetallic supported nickel-containing catalysts modified with chromium $(0)$ compounds and phosphoromolybdic heteropolyacid were prepared. Based on data obtained by chemisorption, 
magnetization, TEM, and XRD, the surface state of catalysts may be presented as Ni nanoparticles $(2-10 \mathrm{~nm})$ covered with chromium nanoparticles (Ni-CrA). The properties of Ni-CrA are quite different from conventional Ni-Cr-catalysts: (1) as opposed to the latter, magnetization of $\mathrm{Ni}-\mathrm{Cr}$ is not decreased by chromium, but significantly increased; (2) it scarcely chemisorbs oxygen; and (3) demonstrates the synergistic activity in hydrogenation of aromatics.

The new catalysts were tested in hydrogenation of benzene, toluene and hydrodemethylation of toluene and they were shown to possess a high activity, selectivity, and sulfur tolerance in the processes above. For toluene hydrodemethylation, their activity was at least ten times more that of commercial catalyst $\mathrm{Cr}_{2} \mathrm{O}_{3} / \mathrm{Al}_{2} \mathrm{O}_{3}$. By selectivity and activity, they are close to Rh-catalysts, but not so expensive, and having much higher sulfur tolerance.

Therefore, the three-component Ni-CrA-LiHPA catalyst was shown to be very promising for hydroconversion of aromatic hydrocarbons and fuels containing thereof and may be scaled-up for industrial applications.

Author Contributions: Conceptualization, V. S. and V.V.; methodology, A.G. and V.S.; software, M.K.; validation, A.G. and P.G.; formal analysis, M.A.; investigation, V.S.; resources, E.I.; data curation, M.K.; writing-original draft preparation, V.S.; writing-review and editing, A.G.; visualization, M.A.; supervision, V.V.; project administration, P.G.; funding acquisition, E.I.

Funding: This work was supported by the Ministry of Education and Science of the Russian Federation (Grant No. 14.Z50.31.0035). Authors thank Yusuf Darrat from Louisiana Tech University (USA) for his input in this work.

Conflicts of Interest: The authors declare no conflicts of interest.

\section{References}

1. Franck, H.; Stadelhofer, J. Industrial Aromatic Chemistry: Raw Materials. Processes. Products; Springer: Berlin, Germany, 1988.

2. Stanislaus, A.; Cooper, B. Aromatic Hydrogenation Catalysis: A Review. Cat. Rev. Sci. Eng. 1994, 36, 75-123. [CrossRef]

3. Kiperman, S.; Cerveny, L. Catalytic hydrogenation. Stud. Surf. Sci. Catal. 1986, 27, 18.

4. Schoenmaker-Stolk, M.; Verwijs, J.; Don, J.; Scholten, J. The catalytic hydrogenation of benzene over supported metal catalysts: II. Gas-phase hydrogenation of benzene over copper-on-silica. Appl. Catal. 1987, 29, 91-105. [CrossRef]

5. Gongbing, Z.; Yanlu, D.; Jiang, L.; He, D.; Yanga, Y.; Zhoua, X. Effect of support composition on the structural and catalytic properties of $\mathrm{Ru} / \mathrm{AlOOH}-\mathrm{SiO}_{2}$ catalysts for benzene selective hydrogenation. Catal. Sci. Technol. 2018, 8, 1435-1446.

6. Goundani, K.; Papadopoulou, C.; Kordulis, C. Benzene elimination from reformate gasoline by high pressure hydrogenation in a fixed-bed reactor. React. Kinet. Catal. Lett. 2004, 82, 149. [CrossRef]

7. Almering, M.; Rock, K.; Judzis, A. Reducing benzene in gasoline. Cost-Effective Solutions for the Reduction of Benzene in Gasoline, Particularly with Regard to MSAT II Requirement. Digitalrefining 2008, 7.

8. Sassykova, L. Development of Catalysts for the Hydrogenation of the Aromatic Ring in Gasolines. Chem. Biochem. Eng. Q. 2017, 31, 447-453. [CrossRef]

9. Abu Bakar, N.H.H.; Bettahar, M.M.; Abu Bakar, M.; Monteverdia, S.; Ismail, J. Low temperature activation of Pt/Ni supported MCM-41 catalysts for hydrogenation of benzene. J. Mol. Catal. A Chem. 2010, 333, 11-19. [CrossRef]

10. Stanley, J.N.G.; Worthington, K.; Heinroth, F.; Masters, A.F.; Maschmeyer, T. Designing nanoscopic, fluxional bimetallic Pt-Ru alloy hydrogenation catalysts for improved sulfur tolerance. Catal. Today 2011, 178, 164-171. [CrossRef]

11. Kim, H.J.; Song, C. Enhancing Sulfur Tolerance of Pd Catalysts by Hydrogen Spillover with Two Different Zeolite Supports for Low-Temperature Hydrogenation of Aromatics. Energy Fuels 2014, 28, 6788-6792. [CrossRef]

12. Tang, T.; Yin, C.; Wang, L.; Ji, Y.; Xiao, F.-S. Good sulfur tolerance of a mesoporous Beta zeolite-supported palladium catalyst in the deep hydrogenation of aromatics. J. Catal. 2008, 257, 125-133. [CrossRef] 
13. Karakhanov, E.; Maximov, A.; Boronoev, M.; Kulikov, L.; Terenina, M. Mesoporous organo-inorganic hybrid materials as hydrogenation catalysts. Pure Appl. Chem. 2017, 89, 1157-1166. [CrossRef]

14. Kniazeva, M.; Maximov, A. Effect of Additives on the Activity of Nickel-Tungsten Sulfide Hydroconversion Catalysts Prepared in Situ from Oil-Soluble Precursors. Catalysts 2018, 8, 644. [CrossRef]

15. Coumans, A.E.; Poduval, D.G.; van Veen, J.A.; Hensen, E.J.M. The nature of the sulfur tolerance of amorphous silica-alumina supported $\mathrm{NiMo}(\mathrm{W})$ sulfide and Pt hydrogenation catalysts. Appl. Catal. A 2012, 411, 51-59. [CrossRef]

16. Comyns, A. Encyclopedic Dictionary of Named Processes in Chemical Technology, 4th ed.; CRC Press: Boca Raton, FL, USA, 21 February 2014.

17. Franck, H.-G.; Stadelhofer, J.W. Industrial Aromatic Chemistry: Raw Materials Processes Products; Springer Science \& Business Media: Berlin, Germany, 2012.

18. Assafi, M.; Duprez, D. Steam-dealkylation and hydrodealkylation of meta-cresol on potassium-promoted rhodium and nickel catalysts. Appl. Catal. A 1992, 80, 23. [CrossRef]

19. Vinokurov, V.; Glotov, A.; Chudakov, Y.; Stavitskaya, A.; Ivanov, E.; Gushchin, P.; Zolotukhina, A.; Maximov, A.; Karakhanov, E.; Lvov, Y. Core Shell Ruthenium-Halloysite Nanocatalysts for Hydrogenation of Phenol. Ind. Eng. Chem. Res. 2017, 56, 14043-14052. [CrossRef]

20. Karakhanov, E.; Maximov, A.; Zolotukhina, A.; Mamadli, A.; Vutolkina, A.; Ivanov, A. Dendrimer-stabilized Ru nanoparticles immobilized in organo-silica materials for hydrogenation of phenols. Catalysts 2017, 7, 86. [CrossRef]

21. Song, Y.; Seo, G.; Ihm, S. Hydrodealkylation reaction of ethylbenzene over a supported Ni-W catalyst. Appl. Catal. A 1992, 83, 75. [CrossRef]

22. Verma, R.K. Aromatics Upgrading Technologies, PEP Report 25. Available online: https://cdn.ihs.com/www/ pdf/RP25E-toc.pdf (accessed on 22 December 2018).

23. Brunelle, J.-P. Hydrodealkylation of Alkylaromatic Hydrocarbons. U.S. Patent 4138443, 6 February 1979.

24. Courty, P.; Page, J.; Sugier, A. Process for Steam Dealkylation of Aromatic Hydrocarbons. U.S. Patent 4199437, 22 April 1980.

25. Lim, D.; Jang, J.; Kim, T.; Shim, S.; Baeck, S.-H. Selective hydrodealkylation of $\mathrm{C}_{9+}$ aromatics to benzene, toluene, and xylenes (BTX) over a Pt/H-ZSM-5 catalyst. J. Mol. Catal. A Chem. 2015, 407, 147. [CrossRef]

26. Stytsenko, V.Surface modified bimetallic catalysts: Preparation, characterization, and applications. Appl. Catal. A. 1995, 126, 1-26. [CrossRef]

27. Gale, W.F.; Totemeier, T.C. Smithells Metals Reference Book; Butterworths: London, UK, 2003.

28. Bozort, R. Ferromagnetism; Wiley-IEEE Press: New York/Piscataway, NJ, USA, 27 August 1993.

29. Victora, R.H.; Falicov, L.M. Calculated electronic structure of chromium surfaces and chromium monolayers on iron. Phys. Rev. B. 1985, 31, 7335-7343. [CrossRef]

30. Bohra, M.; Grammatikopoulos, P.; Diaz, R.E.; Singh, V.; Zhao, J.; Bobo, J.-F.; Kuronen, A.; Djurabekova, F.; Nordlund, K.; Sowwanas, M. Surface Segregation in Chromium-Doped NiCr Alloy Nanoparticles and Its Effect on Their Magnetic Behavior. Chem. Mater. 2015, 27, 3216-3225. [CrossRef]

31. Fidalgo, B.; Arenillas, A.; Menéndez, J.Á. Synergetic effect of a mixture of activated carbon $+\mathrm{Ni} / \mathrm{Al}_{2} \mathrm{O}_{3}$ used as catalysts for the $\mathrm{CO}_{2}$ reforming of $\mathrm{CH}_{4}$. Appl. Catal. A 2010, 390, 78-83. [CrossRef]

32. Bates, M.K.; Jia, Q.; Ramaswamy, N.; Allen, R.J.; Mukerjee, S. Composite Ni/NiO-Cr $\mathrm{O}_{3}$ Catalyst for Alkaline Hydrogen Evolution Reaction. J. Phys. Chem. C 2015, 119, 5467-5477. [CrossRef]

33. Wen, G.; Xu, Y.; Xu, Z.; Tian, Z. Characterization and Catalytic Properties of the $\mathrm{Ni} / \mathrm{Al}_{2} \mathrm{O}_{3}$ Catalysts for Aqueous-phase Reforming of Glucose. Catal. Lett. 2009, 129, 250-257. [CrossRef]

34. Hossein, M.; Shiraz, A.; Rezaei, M.; Meshkani, F. Preparation of nanocrystalline $\mathrm{Ni} / \mathrm{Al}_{2} \mathrm{O}_{3}$ catalysts with the microemulsion method for dry reforming of methane. Can. J. Chem. Eng. 2016, 94, 1177-1183.

35. Kanervo, J.; Harlin, M.E.; Krause, A.; Banares, M. Characterisation of alumina-supported vanadium oxide catalysts by kinetic analysis of H2-TPR data. Catal. Today 2003, 78, 171-180. [CrossRef]

36. Venezia, A.; Parola, V.; Pawelec, B.; Fierrob, J. Hydrogenation of aromatics over $\mathrm{Au}-\mathrm{Pd} / \mathrm{SiO}_{2}-\mathrm{Al}_{2} \mathrm{O}_{3}$ catalysts; support acidity effect. Appl. Catal. A Gen. 2004, 264, 43-51. [CrossRef]

37. Zlotina, N.E. Cand. Sci. (Chem.) Dissertation. Ph.D. Thesis, Inst. Org. Chem. Acad. Sci. USSR, Moscow, Russia, 1967.

38. Stytsenko, V. Kinetic Descriptions of Heterogeneous Catalytic Processes Using Adsorption Substitution Reactions. Russ. J. Phys. Chem. 2018, 92, 228-238. [CrossRef] 
39. Westsson, E.; Koper, G.J. How to Determine the Core-Shell Nature in Bimetallic Catalyst Particles? Catalysts 2014, 4, 375-396. [CrossRef]

40. Richardson, J. Principles of Catalyst Development; Plenum: New York, NY, USA, 1989.

41. Stytsenko, V.; Lee, W.; Lee, J. Catalyst Design for Methacrolein Oxidation to Methacrylic Acid. Kinet. Catal. 2001, 42, 212-216. [CrossRef] 